\section{Commentary: To transplant or not to transplant: Potts shunt as an alternative to pediatric lung transplantation}

\author{
Karthik Thangappan, MD, and \\ David L. S. Morales, MD
}

Lancaster and colleagues ${ }^{1}$ describe the Potts shunt as an acceptable alternative to lung transplantation for refractory pulmonary hypertension (PHTN) in pediatric patients. Until now, the majority of existing literature on this topic came from European experiences. A multicenter study by Baruteau and colleagues ${ }^{2}$ demonstrated $>80 \%$ survival and persistently improving functional status at median followup of approximately 2 years after Potts shunt. Other reports, including a few from US programs, are case reports/series. This article represents the largest North American singleinstitution experience of Potts shunt for PHTN in children.

PHTN in pediatric patients carries significant morbidity and mortality, with median survival $<3$ years from diagnosis if left untreated. ${ }^{3}$ When unresponsive to traditional medical interventions, surgical intervention is pursued. The current standard practice for these patients is lung transplantation, which itself carries significant morbidity and mortality. The median survival after pediatric lung transplant is only 5.7 years, and due to shortages of organs in pediatric populations and the relatively low number of centers offering pediatric lung transplant, waitlist mortality is also significant. ${ }^{4,5}$

\footnotetext{
From the Department of Cardiovascular Surgery, Cincinnati Children's Hospital Medical Center, Cincinnati, Ohio.

Disclosures: Dr Morales is a consultant and member of the medical advisory board for Berlin Heart, Inc; a proctor, instructor, consultant, and member of the medical advisory board for Syncardia, Inc; the national principal investigator for the 50/50cc SynCardia Total Artificial Heart FDA Trial; a consultant for Medtronic, Inc (HeartWare Division); a consultant for Abbott Medical, Inc (Thoratec Division); a consultant for Azyio, Inc; and had stock options (never used) with CorMatrix Cardiovascular, Inc. Dr Thangappan reported no conflicts of interest.

The Journal policy requires editors and reviewers to disclose conflicts of interest and to decline handling or reviewing manuscripts for which they may have a conflict of interest. The editors and reviewers of this article have no conflicts of interest.

Received for publication Nov 14, 2020; revisions received Nov 14, 2020; accepted for publication Nov 16, 2020; available ahead of print Nov 24, 2020.

Address for reprints: David L. S. Morales, MD, Department of Cardiovascular Surgery, Cincinnati Children's Hospital Medical Center, 3333 Burnet Ave, MLC 2004, Cincinnati, OH 45229 (E-mail: David.Morales@cchmc.org).

J Thorac Cardiovasc Surg 2021;161:1149-50

$0022-5223 / \$ 36.00$

Copyright (C) 2020 by The American Association for Thoracic Surgery

https://doi.org/10.1016/j.jtcvs.2020.11.062
}

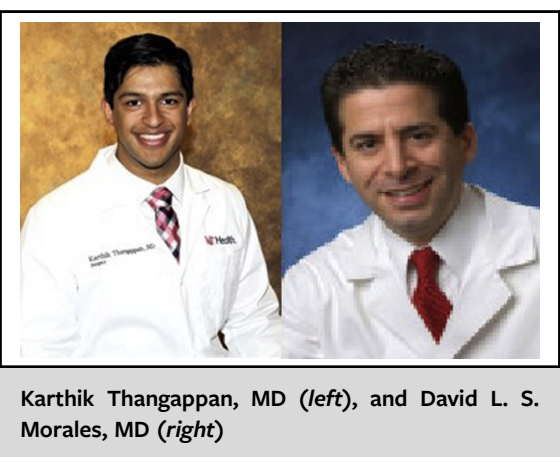

CENTRAL MESSAGE

In the pursuit of less morbidity in

the management of refractory

pediatric pulmonary hyperten-

sion, Potts shunt has been found

to be a feasible and increasingly

popular alternative to lung

transplant.

Physiologically, the Potts shunt in these patients functionally results in Eisenmenger syndrome with a fully saturated upper body. Studies have demonstrated superior survival in Eisenmenger patients (91\% 5-year survival) compared with untreated PHTN patients and lung transplant recipients of whom $>50 \%$ of patients die by 3 and 6 years, respectively. ${ }^{3,4,6}$ Although overall survival was found to be similar between Potts shunt and lung transplant in the current study, the reduction in postoperative complications and consistent improvement in functional status is arguably more important when evaluating the efficacy of a palliative procedure. ${ }^{1}$ The medical burden is also significantly lower in Potts shunt patients (eg, risk of infection, cancer, rejection, and bronchoscopies). This strategy's success makes one wonder whether the Potts shunt may decrease medical burden and cost for certain patients on a triple therapy anti-PHTN regimen.

The technique used for Potts shunt in this study was via direct anastomosis, nonvalved conduit, or valved conduit. The thought process behind a valved conduit is to ensure 1-way blood flow through the shunt, theoretically optimizing its efficacy. There has been no report of a successful bridge from a direct anastomosis Potts shunt to lung transplant in pediatric patients; however, successful transplant has occurred from a conduit Potts. The authors do not comment on differences in outcomes based on anastomosis type, likely due to low sample sizes for statistical comparisons. We believe that the direct anastomosis Potts shunt is 
limiting and should be abandoned because it provides no advantage and makes transplantation not an option.

We commend Lancaster and colleagues ${ }^{1}$ on reporting the largest North American single-institution experience with the Potts shunt compared with lung transplant in the management of PHTN in children. With further development and evolution of the technique, the question of whether to transplant or not to transplant may not need to be mutually exclusive because the Potts shunt will likely develop into a bridge to lung transplant.

\section{References}

1. Lancaster TS, Shahanavaz S, Balzer DT, Sweet SC, Grady RM, Eghtesady P. Midterm outcomes of the Potts shunt for pediatric pulmonary hypertension, with comparison to lung transplant. J Thorac Cardiovasc Surg. 2021;161:1139-48.
2. Baruteau AE, Belli E, Boudjemline Y, Laux D, Lévy M, Simonneau G, et al. Palli ative Potts shunt for the treatment of children with drug-refractory pulmonary arterial hypertension: updated data from the first 24 patients. Eur J Cardiothorac Surg 2015;47:e105-10.

3. D’Alonzo GE, Barst RJ, Ayres SM, Bergofsky EH, Brundage BH, Detre KM, et al. Survival in patients with primary pulmonary hypertension. Results from a national prospective registry. Ann Intern Med. 1991;115:343-9.

4. Hayes D, Cherikh WS, Chambers DC, Harhay MO, Khush KK, Lehman RR, et al. The International Thoracic Organ Transplant Registry of the International Society for Heart and Lung Transplantation: twentysecond pediatric lung and heart-lung transplantation report-2019; focus theme: donor and recipient size match. J Heart Lung Transplant. 2019; 38:1015-27.

5. Goldstein BS, Sweet SC, Mao J, Huddleston CB, Grady RM. Lung transplantation in children with idiopathic pulmonary arterial hypertension: an 18-year experience. J Heart Lung Transplant. 2011;30:1148-52.

6. Niwa K, Perloff JK, Kaplan S, Child JS, Miner PD. Eisenmenger syndrome in adults: ventricular septal defect, truncus arteriosus, univentricular heart. J Am Coll Cardiol. 1999;34:223-32.
See Article page 1139.

\section{Commentary: Will the reversed Potts shunt replace lung transplantation for children with end-stage pulmonary arterial hypertension?}

\author{
Erika B. Rosenzweig, MD, and Emile Bacha, MD $^{\mathrm{b}}$
}

Lancaster and colleagues ${ }^{1}$ should be congratulated on reporting their first 23 pediatric patients with advanced pulmonary arterial hypertension (PAH) undergoing a reversed Potts shunt procedure. Although perioperative mortality and morbidity were relatively high after the reversed Potts

From the ${ }^{\mathrm{a}}$ Division of Pediatric Cardiology and ${ }^{\mathrm{b}}$ Section of Congenital and Pediatric Cardiac Surgery, Division of Cardiothoracic Surgery, Columbia University Irving Medical Center-New York Presbyterian Hospital, New York, NY.

Disclosures: The authors reported no conflicts of interest.

The Journal policy requires editors and reviewers to disclose conflicts of interest and to decline handling or reviewing manuscripts for which they may have a conflict of interest. The editors and reviewers of this article have no conflicts of interest.

Received for publication Nov 4, 2020; revisions received Nov 4, 2020; accepted for publication Nov 5, 2020; available ahead of print Nov 19, 2020.

Address for reprints: Emile Bacha, MD, Section of Congenital and Pediatric Cardiac Surgery, Division of Cardiothoracic Surgery, Columbia University Irving Medical Center-New York Presbyterian Hospital, New York, NY 10032 (E-mail: eb2709@ cumc.columbia.edu).

J Thorac Cardiovasc Surg 2021;161:1150-1

$0022-5223 / \$ 36.00$

Copyright (c) 2020 by The American Association for Thoracic Surgery

https://doi.org/10.1016/j.jtcvs.2020.11.024

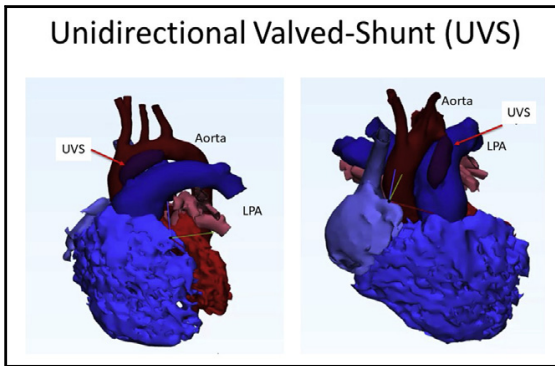

Valved reversed Potts shunt placed between the main pulmonary artery and the distal aortic arch.

CENTRAL MESSAGE

The exact indications for and techniques of the reversed Potts shunt are currently being refined. This shunt is anticipated to play a major role in the management of children with advanced pulmonary hypertension.

shunt, these patients are extremely challenging to manage, and all would have likely died without the reversed Potts shunt or lung transplantation. The authors highlight some of the critical lessons learned in their early experience that led to abandonment of the Potts shunt as a rescue procedure for those sick enough to be on extracorporeal membrane oxygenation (ECMO) preoperatively. In addition to the patients on preoperative ECMO, there 